\title{
PHILOSOPHICAL LINGUISTIC RELATIVITY: SEBUAH KAJIAN TENTANG POKOK PIKIRAN FILSAFAT RELATIVISME BAHASA
}

\author{
L. Angelianawati \\ angelianawati@gmail.com \\ Universitas Kristen Indonesia
}

\begin{abstract}
ABSTRAK
Relativisme adalah kebalikan dari rasionalisme. Dalam kasus ini, teori relativitas bahasa merupakan bagian dari filsafat relativisme. Filsafat ini memandang bahwa bahasa bukanlah sebuah entitas yang statis atau mutlak. Bahasa diyakini dapat mempengaruhi pikiran. Budaya, melalui bahasa, mempengaruhi cara berfikir individu dan bagaimana mereka melihat dunia atau realitas. Konsep dasar dari filsafat ini adalah bahwa bahasa mempengaruhi pikiran, Bahasa bersifat istimewa atau unik, dan bahwa bahasa dan budaya bersifat relatif. Masing-masing konsep memiliki kekuatan, kelemahan, peluang, dan ancaman. Relativisme berimbas pada berbagai aspek kehidupan manusia, khususnya pendidikan. Hal tersebut membawa implikasi pada pendidikan secara umum, dan pembelajaran bahasa, moralitas, pragmatisme dan kurikulum secara khusus, jika dilihat dari sudut pandang pendidikan.
\end{abstract}

Kata Kunci: Relativisme, bahasa, filsafat, relativitas bahasa

\begin{abstract}
Relativism is an antithesis of rationalism. In this case, linguistic relativity belongs to relativism. It views that language is not a static entity. Language is believed influencing thought. Culture, through language, influence the individuals' ways of thinking and how they view the world or realities. The basic concepts of this philosophy are that language dictates thought, language is idiosyncratic or unique, and that language and culture are relative. Each concept has its strengths, weakness, opportunities and threats. Relativism imposes on the various aspects of human life, particularly education. It brings implications on education in general, and on language learning, morality, pragmatism, and curriculum specifically, when it is seen from education point of view.
\end{abstract}

Keywords: Relativism, language, philosophy, linguistic relativity 
PENDAHULUAN

Bahasa adalah bagian dari kehidupan manusia yang bersifat unik. Kemampuan berbahasalah yang menjadi keunikan manusia bukan kemampuannya dalam berpikir, karena untuk berpikir secara sistematis dan teratur, manusia membutuhkan bahasa berikut simbolnya. Selain itu, dengan kemampuan berbahasa manusia membangun budayanya. Dengan bahasa, budaya itu tetap dapat dikomunikasikan antar generasi dan dipertahankan serta dikembangkan (Suriasumantri, 2009).

Budaya melalui bahasa diyakini mampu mempengaruhi cara berpikir manusia. $\mathrm{Hal}$ ini dikenal dengan istilah language relativity atau relativitas bahasa yang merupakan landasan filsafat relativisme bahasa. Konsep ini bersumber pada pemikiran bahwa bahasa sebagai wujud budaya mempengaruhi cara berpikir khususnya tentang pengalaman di dunia (Gumperz dan Levinson, 1999; Wardhough, 2006). Terkait dengan hal tersebut, bahasa mempunyai pengaruh terhadap pengalaman manusia secara perseptual dan konseptual, sekaligus berimplikasi pada meningakatnya komunikasi, meluasnya pemikiran abstrak, membentuk kebudayaan, dan terbentuknya self-concept (Widhiarso, 2005).

Filsafat relativisme bahasa memuat pokok-pokok pikiran yang berimbas pada berbagai aspek kehidupan manusia, baik dalam aspek budaya, sosial, bahkan pendidikan. Pokok-pokok pikiran tersebut berikut implikasinya dalam berbagai aspek kehidupan manusia perlu dijabarkan dengan ekspilisit, sehingga para praktisi dan pemerhati bahasa memiliki wawasan tentang bagimana filsafat relativisme bahasa berimplikasi terhadap kehidupan manusia terutamanya terhadap pendidikan secara umum dan individu yang terlibat secara khusus. Dengan demikian artikel ini dimaksudkan untuk mengkaji secara sederhana tentang pokok-pokok pikiran filsafat relativisme bahasa beserta implikasinya. 
Angelianawati, Philosophical Linguistic Relativity: Sebuah Kajian tentang Pokok Pikiran Filsafat Relativisme Bahasa

PEMBAHASAN

A. Latar Belakang Munculnya Filsafat Relativisme Bahasa

Secara

mendasar, relativisme adalah sebuah pandangan bahwa nilai-nilai dan norma-norma kognitif, moral atau estetika tergantung pada sistem sosial atau konseptual yang mendukung mereka (Baghramian, 2004). Selain itu Zilioli (2007) menyatakan bahwa relativisme bukanlan sebuah doktrin melainkan sebuah kumpulan sudut pandang yang konsep umumnya adalah bahwa aspek utama dari pengalaman, pikiran, evaluasi, dan bahkan kenyataan bersifat relatif.

Filsafat relativisme bahasa berakar dari konsep utama filsafat relativisme. Secara mendasar relativisme adalah filsafat yang tidak mengakui nilai absolut atau kebenaran.

Relativisme merupakan filsafat yang menganggap ilmu pengetahuan, kebenaran dan moralitas dalam kaitannya dengan budaya, masyarakat maupun konteks sejarah, tidak bersifat mutlak. Relativisme mengacu pada hakikat penalaran bahwa apa yang dikatakan benar atau salah; baik atau buruk tidak bersifat mutlak, tapi senantiasa berubah-ubah dan bersifat relatif tergantung pada individu, lingkungan maupun kondisi sosial. Sudut pandang ini dijadikan sebagai pendekatan ilmiah dalam kajian-kajian keilmuan antara lain dalam bidang sosiologi, antropologi, dan bahasa. Pandangan ini sesungguhnya telah lama ada sejak Protagoras, tokoh Sophis Yunani terkemuka abad 5 SM (Shalahuddin, 2007).

Kemunculan dari filsafat relativisme merupakan antithesis dari filsafat rasionalisme. Secara umum, rasionalisme adalah filsafat yang menekankan akal budi (rasio) sebagai sumber utama pengetahuan. Menurut filsafat ini ilmu pengetahuan pada dasarnya adalah suatu sistem deduktif yang dapat dipahami secara rasional, yang hanya secara tidak langsung berhubungan dengan pengalaman indrawi (Bagus, 2000). Menurut rasionalisme, hanya pengetahuan yang diperoleh melalui rasio dan bersifat mutlak yang dituntut oleh semua ilmu pengetahuan. Sedangkan pengalaman hanya 
dapat dipakai untuk mengukuhkan kebenaran pengetahuan yang telah diperoleh melalui akal. Dalam hal ini pengetahuan adalah universal dan tidak terikat oleh waktu. Rasionalisme mendasarkan teorinya dari metode deduksi, yaitu cara memperoleh kepastian melalui langkah-langkah metodis yang bertitik tolak dari hal-hal yang bersifat umum untuk mendapatkan kesimpulan yang bersifat khusus. (Sofyan, 2008).

\section{Sebaliknya,}

relativisme menyatakan bahwa pedoman dalam menilai suatu teori lebih baik dari teori lainnya atau teori sebelumnya tidak ada standar rasionalitas yang universal ataupun mutlak. Apa yang dipandang lebih baik atau lebih buruk tentang suatu teori ilmu akan berbeda-beda menurut individu yang satu dengan yang lainnya. Secara mendasar setiap individu terikat pada subjektivitas (Sofyan, 2008). Seperti disampaikan oleh Schuon (1973) bahwa aksioma dari relativisme adalah seseorang tidak akan pernah bisa lepas dari subjectivitas (the axiom of

relativism is that "one can never escape from human subjectivity").

Dalam perkembangan selanjutnya, filsafat relativisme berkembang dalam berbagai disiplin ilmu, salah satunya adalah bahasa. Munculnya filsafat relativisme bahasa bermula dari munculnya pemikiran para sarjana linguistik yang dimulai sejak awal abad 19 sampai pada pertengahan abad 20. Wilhelm von Humboldt (1767-1835) adalah orang yang dirujuk sebagai bapak relativitas bahasa. Menurut filosof dan bahasawan berbangsa Jerman ini, terdapat saling-hubungan yang erat antara masyarakat, bahasa, dan budaya. Humbolt menegaskan bahwa struktur bahasa berpengaruh terhadap berkembangnya pola-pikir manusia, dan dalam setiap bahasa terkandung pandangan dunia yang khas. la berpandangan bahwa relativitas bahasa berarti suatu bahasa secara mutlak menentukan pola pikir penuturnya. Dalam teorinya, Humbolt menyatakan bahwa bahasa dan pikiran adalah satu kesatuan, dan bahasa bukanlah produk dari pikiran. 
Angelianawati, Philosophical Linguistic Relativity: Sebuah Kajian tentang Pokok Pikiran Filsafat Relativisme Bahasa

Terkait dengan budaya, Humbolt menyatakan bahwa setiap budaya memiliki cara pandangnya tersendiri tentang dunia. (Baghramian, 2004; Christina, 2004)

Di Amerika Serikat, relativisme nampak jelas pada kajian-kajian Bahasa yang dilakukan Franz Boas (1858-1942) terhadap bahasa-bahasa IndianAmerika. Boas tertarik pada bidang antropologi, dan bahasa. Bidang kajiannya yang dominan adalah tentang bahasa dan hubungannya dengan ilmu pengetahuan dan budaya. Berdasarkan hasil penelitiannya ditemukan bahwa setiap bahasa memiliki deskripsinya yang khas, karena setiap bahasa memiliki struktur yang unik. Struktur bahasa tersebut menentukan aspek-aspek dari setiap pengalaman atau realitas yang harus diungkapkan (Slobin, 1999). Dengan kata lain, bahasa mempengaruhi pikiran dan cara memandang dunia atau realitas yang dialami. Tidak ada bahasa yang ideal sebagai model untuk bahasa-bahasa yang lain, karena masing-masing bahasa memiliki struktur bahasa yang unik, yang merepresentasikan nilai-nilai budaya yang dikandungnya. Dalam hal ini, relativitas bahasa adalah bersifat mutlak.

Selanjutnya, pemikiran Boas diwarisi oleh Edward Sapir (1884 1939), dan pemikiran Sapir mempengaruhi muridnya Benjamin Lee Whorf (1897-1941). Edward Sapir mengemukakan pendapat bahwa tidak ada dua bahasa yang cukup sama yang mewakili kenyataan sosial yang sama. Karena bahasa mewakili kenyataan yang berbeda, maka pengguna bahasa tersebut akan menerima kenyataan dengan cara yang berbeda. Kemudian, Benjamin Lee-Whorf, murid dari Edward Sapir, tidak hanya melihat dari sisi bahwa bahasa mempengaruhi pikiran dan prilaku pengguna bahasa. Whorf juga menambahkan bahwa perbedaan sistem tata bahasa dan penggunaan bahasa mempengaruhi cara pengguna bahasa tersebut memahami dunia. Pandangan Whorf mengenai adanya saling ketergantungan antara bahasa dan pikiran dikenal 
dengan hipotesis Sapir-Whorf. Hipotesis Sapir-Whorf lebih tegas menyatakan bahwa struktur bahasa, suatu yang digunakan secara terus menerus akan mempengaruhi pola pikir pengguna bahasa tersebut. Hipotesis ini menunjukkan bahwa bahasa, pikiran, dan budaya berkaitan satu dengan yang lain. Dalam hal ini, bahasa mengatur dunia untuk penuturnya, dan setiap kali bahasa dipelajari dan berkembang, persepsi terhadap dunia juga akan berubah, serta cara berpikirnya (Penn, 1972; Baghramian, 2004; Christina, 2004; Gumperz \& Levinson, 1999). Dalam kaitannya dengan relativisme kebahasaan, Pollard (1997) juga menyatakan bahwa "different languages embody 'distinct realities'". Hal ini menunjukkan bahwa pada setiap bahasa melekat realitas dunia yang unik dan berbeda.

Dengan kata lain, bisa disimpulkan bahwa pengguna bahasa berpikir dengan cara yang berbeda karena bahasa mereka menawarkan cara mengungkapkan (makna) dunia luar di sekitar mereka dengan cara yang berbeda pula. Dan inilah gagasan dasar relativisme bahasa.

\section{B. Pokok-pokok Pikiran Filsafat Relativisme Bahasa}

Filsafat relativisme bahasa memuat beberapa pokok pikiran, yaitu bahwa bahasa mempengaruhi pikiran, bahasa bersifat unik atau khas, dan paradigm apakah Whorf-Sapir Hipotesis: relativitas bahasa atau relativitas budaya (Gumperz \& Levinson, 1999; Widhiarso, 2005; Wardhough, 2006).

\section{Bahasa mempengaruhi}

pikiran. Bahasa mempengaruhi orientasi, yang mana bersifat subjektif dalam menggambarkan pengalaman manusia. Orientasi inilah yang mempengaruhi bagaimana manusia berpikir dan berkata. Pengaruh bahasa terhadap pikiran dapat terjadi melalui pembiasaan dan beroperasinya aspek formal bahasa, dalam hal ini tata bahasa dan kosakata. Whorf mengatakan bahwa tata bahasa dan kosakata menjadi penentu representasi konseptual yang ada dalam 
Angelianawati, Philosophical Linguistic Relativity: Sebuah Kajian tentang Pokok Pikiran Filsafat Relativisme Bahasa

pengguna bahasa tersebut.

yang berbeda akan suatu hal Bahasa-bahasa yang ada di dunia berbeda-beda, karena itu orang yang menggunakan bahasa yang berbeda akan mempunyai cara pandang yang berbeda terhadap suatu hal. Bahasa adalah kunci untuk memahami perbedaan cara pandang manusia terhadap dunia.

Bahasa bersifat unik atau

khas. Setiap bahasa memiliki ciri khasnya tersendiri, yang membuatnya unik. Sebagai contoh, dilihat dari strukturnya, terlihat jelas bahwa bahasa berbeda pada tingkat fonetik, fonemik, morfemik, dan atau sintaktik. Dilihat dari sudut pandang budaya, setiap bahasa mencerminkan nilai - nilai budaya yang berbeda dan bersifat unik.

Relativitas bahasa atau relativitas budaya. Dalam filsafat ini, diyakini bahwa bahasa bersifat relatif demikian juga budaya. Setiap bahasa, yang tak bisa lepas dari lingkup budayanya, muncul di depan kita dengan kekhasan masing-masing. Nilai moral, keindahan, pengetahuan, rasa dan arti adalah bersifat relatif. Setiap orang mempunyai pandangan

\section{Analisis Pokok Pikiran}

Bedasarkan esensi dari pokok-pokok pikiran seperti yang dibahas sebelumnya, setiap pokok pikiran memuat kekuatan, kelemahan, tantangan, dan peluangnya terkait dengan penggunaan bahasa itu sendiri.

Pertama, bahasa mempengaruhi pikiran. Kekuatan, 
Bahasa mempengaruhi pikiran dalam memandang realitas, untuk selanjutnya, pikiran direfleksikan dari kata-kata yang terucapkan. Individu mampu mengungkapkan realitas dengan menggunakan bahasa yang dimilikinya. Semakin kompleks bahasa yang dimiliki dan dikuasai, semakin mampu seorang individu mengungkapkan realitas yang ada, dengan segala kompleksitasnya. Kelemahan, kurangnya kosakata membatasi kreatifitas pikiran. Setiap individu memiliki beban untuk meningkatkan kemampuan bahasanya agar bisa menyampaikan pikirannya tentang dunia termasuk pengalamanpengalamannya. Dalam hal ini, bahasa yang dimaksud tentu tidak hanya simbol-simbol termasuk vocabulary (kosakata) dan grammar (tata bahasa), tetapi juga keterampilan berbahasamendengarkan, berbicara, membaca, dan menulis. Peluang, manusia dapat merealisasikan segala sesuatu dengan bahasa. Semakin luas and kompleks bahasa yang diketahuinya, semakin luas bidang cakupan pengetahuannya, serta komunikasinya dengan orang maupun subjek yang beragam. Tantangan, 1). Keterbatasan bahasa pertama mempengaruhi cara pandang individu terhadap dunianya. Sebagai konsekuensinya, seorang individu mungkin mengalami kesulitan ketika ingin menyampaikan ide atau pemikiranya. Ketika bahasa yang dikuasai sangatlah terbatas dan sederhana, misalnya dari segi kosakata, maka individu tidak mampu mengungkapkan pandangannya tentang sesuatu secara gamblang dan tepat guna. 2). Ketika individu menguasai bahasa yang kompleks dengan baik, bisa saja ia menggunakannya untuk mengeksplorasi pemikirannya dengan berlebihan. Sehingga yang terjadi adalah ucapan yang berlebihan dari individu tersebut.

Kedua, bahasa bersifat unik atau khas. Kekuatan, setiap bahasa memiliki cirinya yang khas yang membuatnya berbeda dari bahasa yang lainnya. Dan dengan sifatnya yang unik bahasa juga membentuk individu yang unik 
Angelianawati, Philosophical Linguistic Relativity: Sebuah Kajian tentang Pokok Pikiran Filsafat Relativisme Bahasa

dengan karakternya yang unik pula. Sehingga setiap individu menjadi special, dengan ciri dan karakternya yang khas. Kelemahan, Bahasa yang sifatnya unik memungkinkan munculnya sikap egoisme (memandang bahasa sendiri yang terbaik atau menggunakan cara pandang bahasanya terhadap bahasa yang lain). Egoisme akan menimbulkan perpecahan antar individu jika keunikan yang ada tidak dipandang sebagai keberagaman yang harus dilestarikan dan dihormati, serta ditoleransi.

Peluang, Bahasa yang unik akan membentuk individu dengan kepribadian yang unik, karena bahasa akan mempengaruhi pikiran individu yang selanjutnya akan berpengaruh pada prilaku mereka. Dan ketika prilaku itu dilakukan secara berulang - ulang terbentuklah karakter dan pada akhirnya menjadi kepribadian. Pembiasaan diri dengan menggunakan bahasa yang baik dan sesuai dengan aturan, akan menumbuhkan pribadi yang baik pula. Tantangan, pemahaman tentang keunikan dalam keberagaman membutuhkan waktu. Dan, menumbuhkan kesadaran akan keunikan masing - masing individu dan membiasakan individu dengan aturan-aturan yang berlaku, baik dalam berbahasa atau berperilaku membutuhkan pelatihan dan pembiasaan. Untuk itu diperlukan adanya kondisi yang mendukung individu, agar mengerti tentang keunikan itu, serta mampu menggunakan dan mengkomunikasikan keunikan itu bersama - sama. Disamping itu dibutuhkan pemahaman yang kuat tentang konteks dimana bahasa itu digunakan untuk menghindari kesalahpahaman, serta salah penggunaan bahasa.

Ketiga, Hipotesis SapirWhorf: relativitas bahasa atau relativitas budaya. Kekuatan, perbedaan pandangan akan suatu hal akan menambah keragaman yang indah jika dilihat dari sisi positifnya. Keberagaman bahasa dan budaya yang bersifat unik menambah kasanah nusantara yang bisa diwariskan dari generasi ke generasi. Kelemahan, perbedaan pandangan dapat 
menimbulkan egoisme yang berujung pada perpecahan. Peluang, perbedaan cara pandang terhadap suatu masalah akan sangat membantu menyelesaikan masalah tersebut dari berbagai sisi. Terutamanya, apabila hal tersebut dilakukan dalam suasana yang demokratis dan saling pengertian, serta dilandasi sikap mau mengkomunikasikan pandangan yang berbeda. Tantangan, mengemukakan pandangan akan suatu hal tanpa menyebabkan ketersinggungan dengan pihak lain membutuhkan latihan dan juga pemahaman tentang demokrasi. Perbedaan pandangan dapat diselesaikan dengan musyawarah mufakat dengan berlandaskan kebijaksanaan dan pemahaman tentang keberagaman itu sendiri. Dalam hal ini, kebijaksanaan dan pemahaman akan keberagaman harus ditanamkan dalam diri setiap individu, dan disadari sepenuhnya hal ini membutuhkan pembiasaan dan itikad yang kuat dari setiap individu.

\section{Implikasi}

Berdasarkan pokok pikiran bahwa bahasa mempengaruhi pikiran serta bersifat unik/ khas, terdapat beberapa hal yang menjadi implikasi filsafat relativisme bahasa, ditinjau dari sudut pandang filsafat relativisme itu sendiri, antara lain mencakup Pendidikan, pembelajaran Bahasa, moralitas, pragmatis, dan kurikulum, sebagai berikut:

\section{Pendidikan (Education)}

Setiap individu bersifat unik, oleh karena itu di dalam pendidikan, perbedaan - perbedaan individu hendaknya diperhatikan dan dihargai. Seperti dijabarkan sebelumnya, bahasa mempengaruhi cara pandang para penggunanya tentang realitas dunia. Dengan demikian, setiap individu memiliki perbedaan cara pandang sesuai dengan bahasa yang dikuasainya. Oleh karena itu, munculnya apresiasi terhadap keberagaman individu dilihat dari bagaimana mereka mengungkapkan realitas suatu objek dalam bahasa sangat diperlukan dalam pendidikan, dan 
Angelianawati, Philosophical Linguistic Relativity: Sebuah Kajian tentang Pokok Pikiran Filsafat Relativisme Bahasa

perbedaan - perbedaan yang ada harus diperhatikan. Dalam pelaksanaan Pendidikan baik di sekolah atau perguruan tinggi, pengelolaan kelas dan pembelajaran hendaknya memperhatikan keberagaman individu peserta didik.

2. Pembelajaran bahasa (Language learning)

Pemerolehan bahasa merupakan usaha yang produktif dan kreatif. Seperti kita ketahui, bahasa adalah instrumen yang membentuk dan membangun ide kreatif dari pikiran. Melalui bahasa ide menjadi objektif. Dari yang semula abstrak dan tidak terungkapkan, ide menjadi konkret dengan adanya bahasa. Dengan demikian munculah keanekaragaman bentuk serta kompleksitas ide sesuai dengan penguasaan bahasa penggunanya sendiri, tingkat kreatifitasnya pun menjadi beragam dari yang paling sederhana sampai yang sangat kompleks. Bentuk kegiatan pembelajaran menjadi beragam menilik kemampuan bahasa siswa yang kompleks dan beragam,

termasuk kreatifitas yang melekat pada diri tiap siswa.

\section{Moralitas}

Pendidikan bahasa bertanggung jawab atas pembentukan identitas (identity forming) dan pencetakan sebuah kepribadian (character buiding). Mengingat bahasa yang bersifat relatif mempengaruhi pikiran dan cara pandang pengguna bahasa, hal ini berimplikasi pada pencetakan kepribadian yang berbeda, karena ketika satu bahasa memproduksi satu perilaku tertentu, dan ketika perilaku tersebut diulang-ulang menjadi kebiasaan maka yang tercipta adalah sebuah kepribadian. Dengan demikian, melalui pendidikan bahasa yang baik, diharapkan terbentuk kepribadian yang baik juga. Pendidik ditantang untuk mengembangkan pembelajaran yang mampu membangun identitas diri dan kepribadian yang berkualitas.

\section{Pragmatis}

Secara pragmatis, bahasa sangat tergantung pada parameter sosial, emosional, dan budaya. Setiap individu memiliki parameter sosial, 
emosional, dan budaya yang berbeda, yang sangat menentukan pemaknaan mereka terhadap sesuatu. Sehingga terkadang, pengguna suatu bahasa memaksakan pandangan konseptualnya, karena secara tak langsung manusia mengevaluasi realita berdasarkan bahasa yang dimiliki. Hal yang tentu saja bisa dihindari apabila meraka memahami dan menyadari bahwa mereka memiliki latar belakang bahasa yang berbeda, dan menyadari apa yang menjadi parameter social, emosional, dan budaya mereka satu sama lain, sehingga nantinya akan muncul sikap menerima dan mau mengkomunikasikan cara pandang dan pikiran yang mungkin berbeda.

\section{Kurikulum}

Kurikulum disesuaikan dengan unsur budaya lokal (Culture based curriculum). Tujuan, isi, dan proses pelaksanaannya disesuaikan dengan kondisi dan karakteristik bahasa peserta didik serta budaya yang dimilikinya. Kurikulum bersifat demokratis, dengan kata lain terdapat pengakuan pluralitas

dengan tetap mengapresiasi unsur - unsur lokal (individu)

Metode: Mengutamakan metode pemecahan masalah, dimana pendidikan berpusat pada siswa (student-centered learning). Demokrasi ditekankan dalam pembelajaran (democraticcooperative learning).

\section{Peranan Pendidik dan Peserta}

didik: Peranan pendidik adalah membimbing peserta didik belajar tanpa terlalu ikut campur atas minat dan kebutuhan siswa. Sedangkan peserta didik berperan sebagai individu yang terus belajar.

\section{KESIMPULAN}

Relativisme bahasa merupakan filsafat bahasa yang menunjukkan kepada kita bahwa setiap bahasa mempunyai ciri khas yang unik secarastruktur dan budaya (every language is unique, structurally and culturally). Setiap bahasa, yang tak bisa lepas dari lingkup budayanya, muncul dengan kekhasan masing-masing. Yang mana, bahasa mempengaruhi cara manusia dalam menangkap serta 
Angelianawati, Philosophical Linguistic Relativity: Sebuah Kajian tentang Pokok Pikiran Filsafat Relativisme Bahasa

mengungkapkan realitas dunia, yang tentu saja bersifat relatif. Dalam hal ini, bahasa mempengaruhi pikiran dan antara bahasa dan budaya saling terkait, Dengan kata lain, budaya, melalui bahasa, mempengaruhi cara berpikir manusia atau individu tentang dunia. Filsafat relativisme bahasa memuat tiga pokok pikiran utama yaitu bahwa bahasa

\section{ACUAN PUSTAKA}

Bagus, L. (2000). Kamus filsafat. Jakarta: PT Gramedia Pustaka Utama

Baghramian, M. (2004). Relativism: The problems of philosophy.

London: Rutledge.

Christina, M. (2004). The linguistic relativity theory and Benjamin Lee Whorf. McMaster Journal of Communication, I(1), 26-31. Diunduh dari https://journals.mcmaster.ca /mjc/article/viewFile/221/188

Gumperz, J. J., \& Levinson, S. C. (1999). Introduction: Linguistic relativity reexamined. In J. J. Gumperz, \& S. C. Levinson (Eds.), Rethinking linguistic mempengaruhi pikiran, bahasa bersifat unik, dan adanya relativitas bahasa dan budaya. Setiap pokok pikiran tersebut memiliki kekuatan, kelemahan, peluang dan tantanganya terkait dengan kehidupan manusia sebagai individu dan terhadap dunia pendidikan, serta memiliki implikasi terhadap dunia kebahasaan, dan moralitas.

relativity. Cambridge University Press.

Penn, J. M. (1972). Linguistic relativity versus innate ideas: The origins of the Sapir-Whorf Hypothesis in German thought. The Hague: Mouton.

Pollard, D. (1997). Picture theory of meaning. In $P$. V. Lamarque (Ed.), Concise encyclopedia of philosophy of language. Pergamon.

Schuon, F. (1973). The contradiction of Relativism. Studies in Comparative Religion, 7(2). Diunduh dari https://www.scribd.com/doc ument/179975645/FrithiofSchuon-The-Contradictionof-Relativism-pdf

Shalhuddin, H. (2015, June 24). Bahaya relativisme 
Angelianawati, Philosophical Linguistic Relativity: Sebuah Kajian tentang Pokok Pikiran Filsafat Relativisme Bahasa

terhadap

keimanan.

Diunduh 7 Juli, 2017, dari

https://www.kompasiana.co

m/ekohape/bahaya-

relativisme-terhadap-

keimanan 5529c3706ea834 $\underline{210 \mathrm{e} 552 \mathrm{~d} 07}$

Slobin, D. L. (1999). From 'thought and language' to 'thinking for speaking'. In J. J. Gumperz, \& S. C. Levinson (Eds.), Rethinking linguistic relativity. Cambridge: Cambridge University Press.

Sofyan, A. (2008). Rasionalisme lawan relativisme. - : Diunduh dari http://andisofyangendoet.blogspot.com/2008/ 02/rasionalisme-lawanrelativisme.html

Suriasumantri, J. S. (2009). Filsafat ilmu: Sebuah pengantar pupuler. Jakarta: Pustaka Sinar Harapan.
Widhiarso, W. (2005). Pengaruh bahasa terhadap pikiran kajian hipotesis Benyamin Whorf dan Edward Sapir. Diunduh 25 Nopember 2010 dari:

http://widhiarso.staff.ugm.ac id/files/hubungan antara b ahasa dan pikiran.pdf

Wardhaugh, R. (2006). An introduction to Sociolinguistics. Oxford: Blackwell.

Zilioli, U. (2007). Protagoras and the challenge of Relativism (Ashgate new critical thinking in Philosophy). Hampshire, England: Ashgate. 